10,07

\title{
Эволюция кривых дифракционного отражения рентгеновских лучей в кристаллах парателлурита и фторида лития при воздействии интенсивным ультразвуком
}

\author{
(C) А.Е. Благов ${ }^{1,2}$, Ю.В. Писаревский ${ }^{1,2}$, А.В. Таргонский ${ }^{1,2}$, Я.А. Элиович ${ }^{1,2}$, М.В. Ковальчук ${ }^{1,2}$ \\ ${ }^{1}$ Федеральный научно-исследовательский центр „Кристаллография и фотоника“ РАН, \\ Москва, Россия \\ ${ }^{2}$ Национальный исследовательский центр „Курчатовский институт“, \\ Москва, Россия \\ E-mail: blagov_ae@nrcki.ru
}

(Поступила в Редакцию 3 октября 2016 г.)

Проведены исследования локальных деформаций кристаллической решетки в условиях ультразвуковой нагрузки в широком диапазоне значений амплитуд с помощью регистрации кривых дифракционного отражения (КДО, rocking curve: $\mathrm{RC}$ ) рентгеновских лучей от монокристаллов парателлурита и фторида лития.

Работа выполнена при поддержке РФФИ (гранты № 14-22-01042 офи_м, 16-29-14057 офи_м, 16-32-60045 мол_а_дк).

DOI: 10.21883/FTT.2017.05.44385.367

\section{1. Введение}

Ультразвуковые колебания (УЗ) больших амплитуд, так же как и статические механические нагрузки, как известно, воздействуют на дефектную структуру кристаллов, вызывая сначала перемещение, а затем и размножение точечных дефектов и дислокаций $[1,2]$.

В подавляющем большинстве работ, посвященных этой области, исследования дефектной структуры проводились лишь в состояниях „до“ и ,после“ внешнего воздействия [3-5]. Исключением могут являться измерения характерных параметров материалов, таких как декремент затухания, в процессе ультразвуковых воздействий [6]. К сожалению, эти параметры характеризуют образец в целом, и их явно недостаточно для детального исследования физических процессов, происходящих при воздействии ультразвука больших амплитуд на кристаллы.

В настоящей работе измерялись кривые дифракционного отражения рентгеновских лучей (КДО) от кристаллов фторида лития и парателлурита, в которых возбуждались ультразвуковые колебания. Известно, что форма и ширина КДО на полувысоте (полуширина КДО) являются общепринятыми характеристиками степени совершенства кристалла [7], а в случае внешних воздействий на исследуемый образец позволяют оценить их влияние на дефектную структуру.

\section{2. Постановка эксперимента}

Измерения проводились на лабораторной экспериментальной установке [8], схема которой приведена на рис. 1. Источником излучения служила линейчатая острофокусная рентгеновская трубка отпаянного типа с молибденовым анодом.
Для проведения исследований использовались рентгенооптические элементы: две коллимирующие щели и статичный кремниевый кристалл-монохроматор (рефлекс 220). Данный набор позволяет использовать в эксперименте рентгеновский пучок спектральной линии Мо $K_{\alpha_{1}}$ для проведения локальных измерений (проекция пучка на образце $0.1-0.2 \mathrm{~mm}$ ). Интенсивность дифрагированного образцом пучка регистрировалась сцинтилляционным одномерным детектором.

При подаче переменного электрического сигнала за счет обратного пьезоэффекта в образце возбуждается стоячая акустическая волна растяжения-сжатия, при этом распределение амплитуды деформации в общем случае представляет собой половину синусоиды [9]. В экспериментах рентгеновский пучок был направлен на область кристалла с однородной ультразвуковой деформацией. Для определения однородной области проводилось предварительное исследование распределения амплитуды деформации, представляющее собой измерение серии КДО при последовательном перемещении

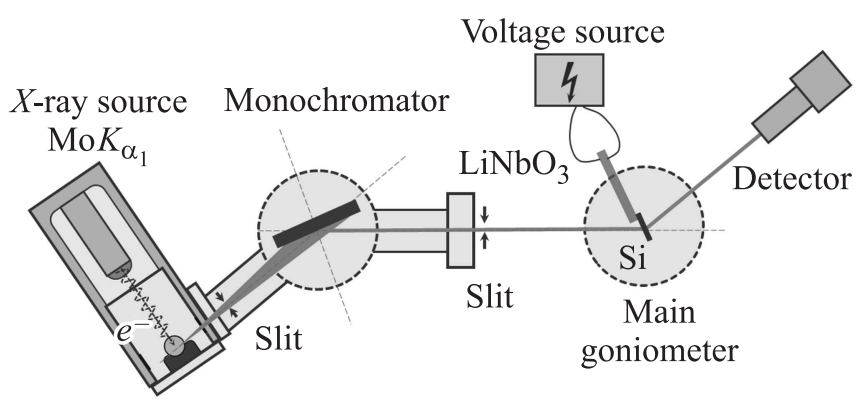

Рис. 1. Рентгенооптическая схема эксперимента по исследованию локальных деформаций кристаллической решетки с помощью измерения КДО в условиях ультразвуковой нагрузки. 

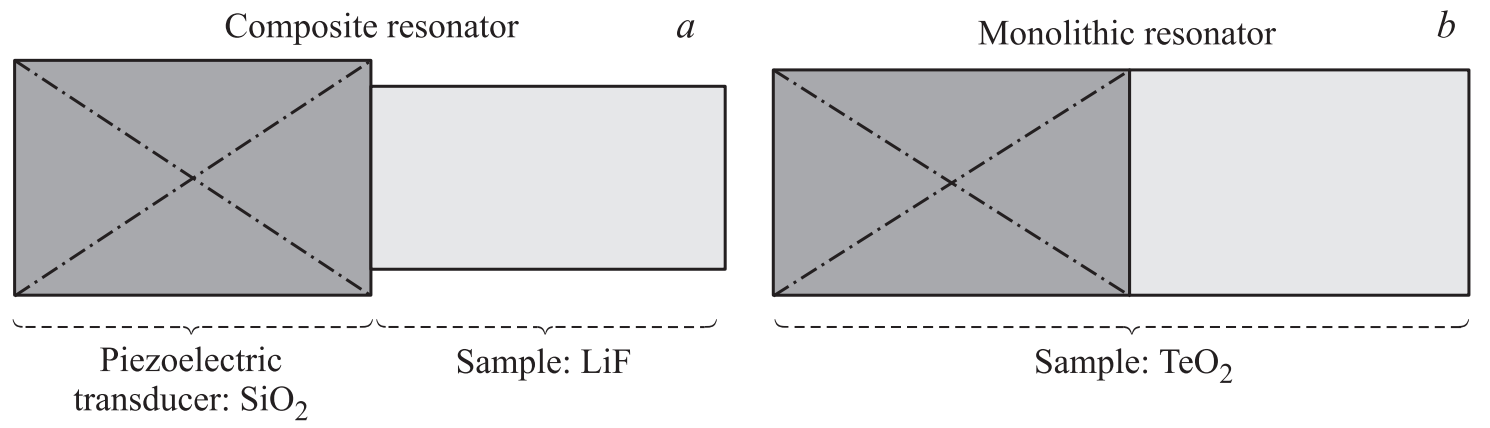

Рис. 2. Схематичное изображение рентгеноакустических элементов: (a) на основе кристаллов фторида лития и кварца (составной); (b) на основе кристалла парателлурита (монолитный).

пучка вдоль поверхности кристалла [10]. Ультразвуковые колебания решетки вызывают увеличение полуширины КДО, пропорциональное амплитуде деформаций. Таким образом, измерение полуширины КДО при включенном ультразвуке позволяет определить деформацию кристаллической решетки в данной области кристалла и ее зависимость от амплитуды подаваемого электрического сигнала, возбуждающего ультразвук.

С использованием описанных рентгенооптических схем были проведены эксперименты по изучению эволюции КДО кристаллов. Временное разрешение, достигнутое в эксперименте (время измерения одной кривой) составляло около $30 \mathrm{~s}$, что позволило наблюдать динамику медленного изменения дефектной структуры в результате образования и релаксации дефектов в условиях ультразвукового воздействия. Метод оказался эффективным для исследования как совершенных, так и несовершенных кристаллов, с большим количеством дефектов, приводящих к значительному уширению КДО.

\section{3. Образцы}

Для исследования кристаллов в условиях ультразвуковой нагрузки применялись специальные элементы рентгеноакустической оптики - составные и монолитные резонаторы [11], в которых возбуждалась стоячая волна растяжения-сжатия на основной резонансной частоте.

Достоинством предлагаемого метода является возможность проведения исследований практически любых кристаллов. Конструкция составного резонатора позволяет эффективно нагружать исследуемые кристаллы с помощью внешнего кристалла-пьезопреобразователя, например, кварца (рис. 2, a). При этом образец может не обладать пьезоэлектрическими свойствами. Если же исследуемый кристалл представляет собой пьезоэлектрик с высоким коэффициентом электромеханической связи (от $10 \%$ ), то можно использовать иную, монолитную конфигурацию (рис. 2,b). В таком случае одна половина используется как возбудитель колебаний, для чего на нее наносятся электроды, а вторая половина кристалла используется для дифракции рентгеновских лучей.
К преимуществам монолитной конфигурации можно отнести высокую надежность, простоту изготовления и отсутствие склеивающего слоя, который дополнительно деформирует образец и поглощает часть энергии колебаний от пьезопреобразователя.

В настоящей работе проводились исследования технически важных кристаллов фторида лития и парателлурита, широко применяемых в оптике и акустоэлектронике.

Фторид лития - кристалл, не обладающий пьезоэлектрическими свойствами. Для возбуждения УЗ-колебаний к нему был приклеен пьезопреобразователь из кристалла кварца.

Кристаллы парателлурита обладают пьезоэлектрическими свойствами, поэтому для возбуждения ультразвуковых колебаний была использована монолитная конфигурация резонатора.

Кристалл фторида лития, размеры которого $19.4 \times 9 \times 1 \mathrm{~mm}$, исследовался в геометрии Лауэ, отражение (200). Кристалл парателлурита с размерами $29 \times 8 \times 0.5 \mathrm{~mm}$ исследовался в геометрии Брэгга, отражение (220). Были проведены измерения и исследования эволюции КДО монокристаллов фторида лития и парателлурита при воздействии ультразвука в широком диапазоне значений амплитуд, а также исследованы временные зависимости при постоянных значениях амплитуд ультразвука.

\section{4. Результаты измерений}

Полученные зависимости полуширины КДО в условиях ультразвуковой нагрузки в интегральном режиме записи были пересчитаны в относительную деформацию кристаллической решетки. Зависимость относительной деформации от амплитуды ультразвукового воздействия для кристалла фторида лития показана на рис. 3, $a$. Начиная с амплитуды подаваемого сигнала $75 \mathrm{~V}$, наблюдается нелинейная зависимость, которая обычно сопровождается перемещением и размножением дефектов.

В кристаллах парателлурита в экспериментах по исследованию амплитудных зависимостей за линейным участком роста деформации при дальнейшем увели- 

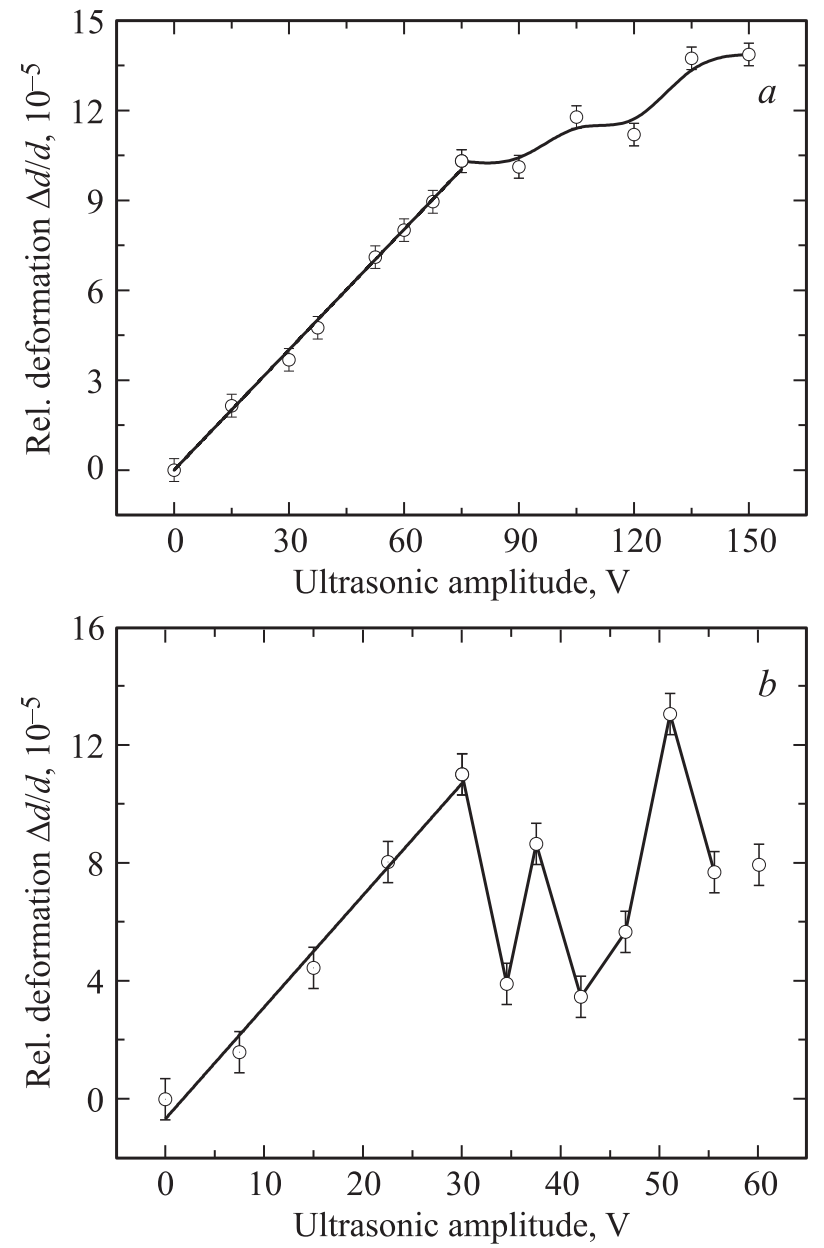

Рис. 3. Зависимости относительной деформации от амплитуды ультразвукового воздействия: $(a)$ для кристалла фторида лития; $(b)$ для кристалла парателлурита.

чении амплитуды электрического сигнала свыше $30 \mathrm{~V}$ также следовал нелинейный участок (рис. $3, b$ ).

Также проводились исследования поведения кристаллов от времени при постоянном значении амплитуды, для чего была выполнена серия последовательных измерений КДО в одной точке кристалла. Зарегистрированные зависимости относительной деформации кристаллической решетки от времени при включении и отключении ультразвука постоянной амплитуды для кристалла фторида лития и парателлурита показаны на рис. $4(a, b)$ соответственно. При этом кристалл фторида лития исследовался при амплитуде $75 \mathrm{~V}$, что соответствует пограничной области между линейным и нелинейным участком, а кристалл парателлурита при $45 \mathrm{~V}$, что соответствует нелинейной части.

Из рис. 4, $a$ хорошо видно, что при возбуждении ультразвуковых колебаний в кристаллах фторида лития, в течение $\sim 20 \mathrm{~min}$ происходит двухстадийный процесс роста амплитуды деформации с образованием промежуточного „метастабильного участка“ при значении относительной деформации $\Delta d / d=4.1 \cdot 10^{-5}$ и переходом в стабильное состояние при деформации $\Delta d / d=7.8 \cdot 10^{-5}$.

При отключении ультразвука в кристалле также наблюдаются две стадии релаксации: сначала кристалл быстро переходит в „метастабильное“ состояние со значением относительной деформации около $\Delta d / d=4.1 \cdot 10^{-5}$, а затем в течение нескольких часов происходит релаксация до начального состояния.

Для кристалла парателлурита (рис. 4,b) при фиксированной амплитуде возбуждающего электрического сигнала $45 \mathrm{~V}$ был обнаружен сложный многостадийный процесс раскачки, подтверждающий сложный характер поведения кристалла в условиях ультразвуковых нагрузок, а также процесс релаксации при отключении переменного электрического поля.
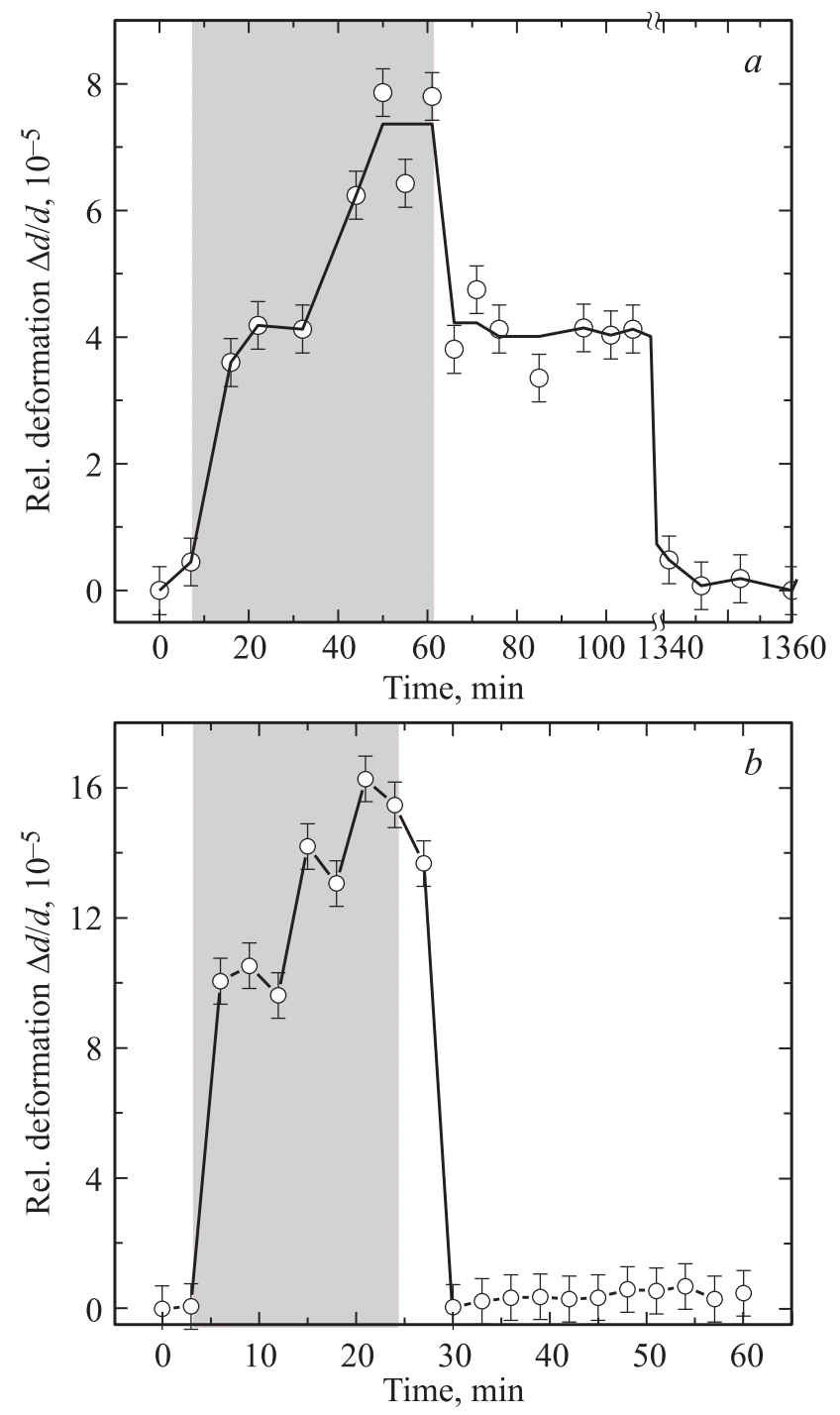

Рис. 4. Зависимости амплитуды деформации от времени воздействия ультразвука постоянной амплитуды: (a) для кристалла фторида лития составного резонатора $\mathrm{SiO}_{2}+\mathrm{LiF}(200)$; серые области - У3 включен, амплитуда $75 \mathrm{~V}$; $(b)$ для монолитного элемента $\mathrm{TeO}_{2}$ (440); серые области — УЗ включен, амплитуда $45 \mathrm{~V}$. 


\section{5. Обсуждение результатов}

Традиционной сложностью при проведении подобных экспериментальных исследований является невозможность точно установить значение амплитуды установившихся колебаний в исследуемом образце при известном значении амплитуды подаваемого сигнала. Однако в данном случае, с помощью предлагаемого коллективом авторов метода, была показана реальная деформация кристаллической решетки, оценка которой была проведена с помощью экспериментов по наблюдению за сдвигом КДО, который затем был пересчитан в относительную деформацию решетки.

В результате проведенных экспериментов обнаружены изменения дефектной структуры кристаллов фторида лития и парателлурита, которые свидетельствуют об изменении внутренних напряжений во времени (и пространстве) из-за интенсивного образования (и релаксации) дефектов в условиях ультразвуковой нагрузки. Важно отметить, что даже при высоких значениях амплитуд модулирующего ультразвука не наблюдалось необратимого ухудшения качества или разрушения кристаллов.

\section{6. Заключение}

В кристаллах $\mathrm{TeO}_{2}$ и $\mathrm{LiF}$ при больших ультразвуковых амплитудах обнаружено образование дефектов, которые полностью рефлексируют при отключении ультразвука. Определены временны́е и амплитудные характеристики данных процессов.

Одним из основных достоинств предложенного метода является возможность исследования дефектной структуры кристаллов в условиях вибрационных нагрузок на ранних стадиях зарождения дефектов, когда не происходит необратимого ухудшения качества и, следовательно, традиционные методы по сути неприменимы.

В настоящей работе исследовалось образование и релаксация дефектов, вызванных ультразвуковым воздействием, происходящих за времена порядка минут и более. Изучение более быстрых изменений возможно при улучшении временного разрешения, которое может быть осуществлено за счет использования адаптивных элементов рентгеноакустической оптики [12-14].

\section{Список литературы}

[1] Н.А. Тяпунина, Г.М. Зиненкова, Е.К. Наими. Действие ультразвука на кристаллы с дефектами. Изд. МГУ, М. (1999). $238 \mathrm{c}$.

[2] Г.Я. Базелюк, И.Г. Полоцкий. Физика металлов и металловедение 5 (1960). С. 56.

[3] Ю.П. Пшеничнов. Выявление тонкой структуры кристаллов. Металлургия, М. (1974). 528 с.

[4] Г.В. Бушуева, Г.М. Зиненкова, Н.А. Тяпунина, В.Т. Дегтярев, А.Ю. Лосев, Ф.А. Плотников. Кристаллография 53, 3 (2008). C. 507.

[5] У. Спенсер. Физическая акустика. Мир, М. (1973). С. 134.
[6] Н.А. Тяпунина, В.Л. Красников, Э.П. Белозерова, В.Н. Виноградов. ФТТ 451 (2003). С. 95.

[7] М.В. Ковальчук, С.И. Желудева, В.Л. Носик. Природа 2 (1997). C. 54.

[8] М.В. Ковальчук, Э.К. Ковьев, Ю.М. Козелихин, А.В. Миренский, Ю.Н. Шилин. Приборы и техника эксперимента 1 (1976). C. 194.

[9] А.Е. Благов, М.В. Ковальчук, Ю.В. Писаревский, В.Г. Кон. Кристаллография 51, 5 (2006). С. 779.

[10] А.Е. Благов, М.В. Ковальчук, В.Г. Кон, В.В. Лидер, Ю.В. Писаревский. ЖЭТФ 128, 5(11) (2005). С. 893.

[11] А.Е. Благов, А.Н. Даринский, М.В. Ковальчук, Ю.В. Писаревский, П.А. Просеков, А.В. Таргонский. Акустический журнал 59, 5 (2013). С. 561.

[12] М.В. Ковальчук, А.В. Таргонский, А.Е. Благов, И.С. Занавескина, Ю.В. Писаревский. Кристаллография 56, 5 (2011). C. 886.

[13] А.Е. Благов, П.А. Просеков, А.В. Таргонский, Я.А. Элиович. Кристаллография 60, 2 (2015). С. 189.

[14] А.Е. Благов, А.С. Быков, И.В. Кубасов, М.Д. Малинкович, Ю.В. Писаревский, А.В. Таргонский, Я.А. Элиович, М.В. Ковальчук. ПТЭ 5 (2016). С. 109. 